\title{
Study of Effect of Nutrition and Sunlight Exposure on Bone Mineral Density in and Around Kanchipuram District
}

Gopalakrishnan $^{{ }^{*}}{ }^{*}$, Sivakumar $\mathrm{J}^{2}$ and K.Ponnazhagan ${ }^{3}$

${ }^{1}$ Assistant Professor, Department of Biochemistry, Meenakshi Medical College Hospital and Research Institute, Enathur, Kanchipuram, Tamilnadu631552, India

${ }^{2}$ Associate Professor, Department of Biochemistry, Dhanalakshmi Srinivasan Medical College and Hospital, Perambalur, Tamilnadu-621212, India

${ }^{3}$ Research Scholar, Department of Biochemistry, Meenakshi Medical College Hospital and Research Institute, Enathur, Kanchipuram, Tamilnadu631552, India

DOI: $10.36348 /$ sijb.2020.v03i10.004
*Corresponding author: Gopalakrishnan

| Received: 10.09.2020 | Accepted: 23.09.2020 | Published: 29.10.2020

\section{Abstract}

Objectives: The aim of the present study was to investigate the relationship between nutrition and sunlight exposure on BMD levels in different age group between 30 to 75 years old subjects and to assess the relationship between age, sex and BMD in general population. Design: An observational cross sectional study of randomly selected in kanchipuram district aged from 30-75 years. Materials and methods: The study was conducted in the department of biochemistry, Meenakshi Medical College Hospital and Research Institute, Kanchipuram .Under this cross-sectional comparative study. 80 subjects of both sexes were subjected to the study. And subjects are divided into group 1(Age Group between 30-45), group 2 (Age Group between 46-60), and group 3 (Age Group between 61-75). Nutrition status and exposure to sunlight was collected by questionaries. Results: 80 adults between 30 to 75 years of both sexes were subjected to this study. People in the age group of 30-45 years were found to be more osteopenic particularly very high in females (males $0.97 \pm 1.2$ and females $-1.3 \pm 1.45$ ) and people in the age group 61 to 75 years, were found to be osteoporotic (males $1.43 \pm 1.3$ and females $-2.08 \pm 0.95)$. Based on nutrition, 15 people of both sexes were selected who are vegetarian $(-0.96 \pm$ 0.6), 22 people were selected who take non-veg three times in a week $(1.29 \pm 0.92)$, and 28 people were selected who take non veg more than 3 times in a week $(1.3 \pm 0.77)$ and 15 people were selected who take both veg and non-veg in a week $(1.38 \pm 0.77)$. The results indicate that vegetarian taking people were got low BMD levels when compared to other groups. BMD level significantly increased in people exposed to sunlight for more than 10 minutes when compared to less exposed to sunlight. Conclusion: This study confirms that people of younger age group (30-45 years) are found to be more osteopenic when compared to the older age group (46-60 years) due to of less exposure in sunlight and low intake of vitamin D and calcium diets. Highlight of this study is "Osteopenia is more prevalent in the younger age group which necessitates earlier intervention"

Key words: BMD, Sunlight, Nutrition, Osteoporosis and Osteopenia.

Copyright (0) 2020 The Author(s): This is an open-access article distributed under the terms of the Creative Commons Attribution 4.0 International License (CC BY-NC 4.0) which permits unrestricted use, distribution, and reproduction in any medium for non-commercial use provided the original author and source are credited.

\section{INTRODUCTION}

Osteoporosis is a significant health problem characterized by low bone density and micro architectural deterioration of bone tissue with a consequent increase in bone fragility and susceptibility to fractures. Measurement of BMD can be used to determine fracture risk and monitor the effects of treatment. Early detection of bone loss is essential to preventing osteoporosis. Worldwide, osteoporosis causes more than 8.9 million fractures annually, resulting in an osteoporotic fracture every 3 seconds [1]. 1 in 3 women over age 50 will experience osteoporotic fractures as well 1 in 5 men aged over 50 [2-4].

The lifetime risk for hip, vertebral, and forearm (wrist) fractures has been estimated to be around $40 \%$, very close to that for coronary heart disease. Osteoporosis does not only cause fractures, but also causes people to become bedridden and causes back pain and loss of height. Prevention of the disease and its associated fractures is important for maintaining health, quality of life, and independence among the elderly. 
A profound change in bone mineral compositions occurs with advancing age and rates of fracture increase with age, giving rise to significant morbidity and mortality [5]. Aging leads to the loss of bone mass which is associated with structural and metabolic deterioration [6]. The degree of bone mineralization is governed by hormonal, nutritional and mechanical factors.

Generally, osteoporosis is three times more common in women than in men and this gap widens with increase in age. Additionally, women have a lower peak bone mass and hormonal changes occur at the menopause. This accelerated loss is associated with the withdrawal of estrogen which begins at about age 40 years in both genders. Thus, in females and males, estrogen has both a catabolic and anabolic effect on bone throughout life, even at 80 to 90 years of age [7].

Vitamin D is taken for granted and is assumed to be plentiful in a healthy diet. Unfortunately, very few foods naturally contain vitamin $\mathrm{D}$, and only a few foods are fortified with vitamin $\mathrm{D}$. This is the reason why vitamin $\mathrm{D}$ deficiency has become epidemic for all age groups in the world. Vitamin D deficiency results in abnormalities in both calcium and phosphorus metabolism. The major function of vitamin $\mathrm{D}$ is to maintain serum calcium concentrations within the physiologically acceptable range. It accomplishes this by increasing intestinal calcium absorption. In a vitamin D-deficient state, the intestine typically absorbs $10-15 \%$ of dietary calcium [8]. In a vitamin D-sufficient state, $30 \%$ typically is absorbed from the diet; as much as 60$80 \%$ can be absorbed during periods of growth and pregnancy or lactation, with increased demand for calcium.

Vitamin D is recognized as the sunshine vitamin. Sun exposure leads to an increase in bone mass and a decrease in falls. Sun exposure also synthesis vitamin $\mathrm{D}$ which is regulating the calcium and phosphorus metabolism. Sunlight exposure and vitamin $\mathrm{D}$ deficiency is increasing both in rural and urbhan populations. Nutrition plays an important role in bone health. The two nutrients essential for bone health are calcium and vitamin D. Reduced supplies of calcium are associated with a reduced bone mass and osteoporosis, whereas a chronic and severe vitamin D deficiency leads to osteomalacia, a metabolic bone disease characterized by a decreased mineralization of bone.

\section{AIM AND OBJECTIVES}

The aim of the present study was to investigate the relationship between nutrition and sunlight exposure on BMD levels in different age group between 30 to 75 years old subjects and to assess the relationship between age, sex and BMD in general population.

\section{MATERIAL AND METHODS}

The study was conducted in the department of biochemistry, Meenakshi Medical College Hospital and Research Institute, Kanchipuram. Under this crosssectional comparative study. 80 subjects of both sexes were subjected to the study. And subjects are divided into group 1(Age Group between 30-45), group 2 (Age Group between 46-60), and group 3 (Age Group between 61-75). Nutrition status and exposure to sunlight was collected by questionaries.

\section{Inclusion criteria}

1. Adults in the age group between 30 to 75 years.

2. Random without any accountlness.

\section{Exclusion criteria}

1. People who take Vitamin D and calcium supplements

2. People who suffer from acute or chronic conditions which interferes with calcium absorption.

3. Pregnant woman.

4. Recent fraction of bone.

\section{METHODOLOGY}

After obtaining permission from institutional ethical committee and the study was conducted on 80 subjects of both sexes, selected for 30-75 years age, by simple random sampling. Bone mineral density (BMD) was measured by ultrasound bone densitometer which included following steps.

\section{Examination technique}

Bone densitometry of the foot was done by PHOTON absorptiometry and BMD calculated. In describing the interaction of electromagnetic radiation with tissue, it is helpful to use an alternative to the wave representation. In this alternative quantum description, the radiation is regarded as small packets of energy called photons. At the energies used in bone densitometry. The normal $\mathrm{T}$ - score -1 and above, osteopenia between -1 and -2.5 , osteoporosis- 2.5 and below.

\section{STATISTICAL ANALYSIS}

The calculation and statistical analysis were carried out using the Statistical Package for Social Sciences (SPSS) for Windows version 21.0 software, one-way ANOVA method and the group mean were compared by Duncan's Multiple Range Test (DMRT). Statistical probability $\mathrm{P}<0.05$ was considered to be significant.

\section{RESULT}

80 adults between 30 to 75 years of both sexes were subjected to this study (table 1). 25 males in this group $(0.44 \pm 1.0)$ and 20 females in this group $(0.62 \pm$ 0.98 ) were found to be normal. 11 males in this group (- 
$1.5 \pm 0.26)$ and 15 females in this group $(-1.7 \pm 0.42)$ were found to be osteopenic. 4 males in this group (-
$2.65 \pm 0.29)$ and 5 females in this group $(-2.82 \pm 0.32)$ were found to be osteoporotic.

Table-1: Bmd distribution in relation to gender

\begin{tabular}{|l|c|c|}
\hline Gender & $\begin{array}{c}\text { Number of } \\
\text { Subjects }\end{array}$ & $\begin{array}{c}\text { Mean } \pm \\
\text { SD values }\end{array}$ \\
\hline Male & 40 & $-0.41 \pm 1.4$ \\
\hline Female & 40 & $-0.71 \pm 1.6$ \\
\hline
\end{tabular}

Age subjects are divided into three categories (Table 2); first group 30-45 years, second group 46-60 years and third group 61-75 years. People in the age group 30-45 years were found to be more osteopenic ($1.2 \pm 1.35)$ and in the age group 61-75 years were found to be more osteoporotic $(-1.7 \pm 1.2)$.

Table-2: BMD distribution in relation to different age group

\begin{tabular}{|l|c|l|}
\hline Age groups & Number of subjects & Mean \pm SD values \\
\hline $30-45$ years & 35 & $-1.2 \pm 1.35$ \\
\hline $46-60$ years & 25 & $-0.65 \pm 1.5$ \\
\hline $61-75$ years & 20 & $-1.7 \pm 1.2$ \\
\hline
\end{tabular}

Table 3 shows, People in the age group of 3045 years were found to be more osteopenic particularly very high in females (males $-0.97 \pm 1.2$ and females $1.3 \pm 1.45$ ) and people in the age group 61 to 75 years, were found to be osteoporotic (males $-1.43 \pm 1.3$ and females $-2.08 \pm 0.95$ ) but people in the age group 46-60 years, were found to be normal (male $-0.86 \pm 1.3$ and female $-0.45 \pm 1.6$ ).

Table-3: BMD distribution in relation to different age group and gender

\begin{tabular}{|l|c|c|l|c|}
\hline Age group & Gender & Number of subjects & Mean \pm SD values & P -value \\
\hline \multirow{2}{*}{$30-45$ years } & Male & 16 & $-0.97 \pm 1.2$ & \multirow{2}{*}{$\mathbf{0 . 0 4}$} \\
\cline { 2 - 5 } & Female & 19 & $-1.3 \pm 1.45$ & \multirow{2}{*}{$<\mathbf{0 . 0 5}$} \\
\hline \multirow{2}{*}{$46-60$ years } & Male & 12 & $-0.86 \pm 1.3$ & \multirow{2}{*}{$<0.05$} \\
\cline { 2 - 5 } & Female & 13 & $-0.45 \pm 1.6$ & \\
\hline \multirow{2}{*}{$61-75$ years } & Male & 10 & $-1.43 \pm 1.3$ & \\
\cline { 2 - 5 } & Female & 10 & $-2.08 \pm 0.95$ & \\
\hline
\end{tabular}

Table 4 shows, 15 people of both sexes were selected who are vegetarian $(-0.96 \pm 0.6), 22$ people were selected who take non-veg three times in a week (1.29 \pm 0.92$)$, and 28 people were selected who take non veg more than 3 times in a week $(1.3 \pm 0.77)$ and
15 people were selected who take both veg and non-veg in a week $(1.38 \pm 0.77)$. The results indicate that vegetarian taking people were got low BMD levels when compared to other groups.

Table-4: BMD distribution in relation to nutrition

\begin{tabular}{|l|c|l|}
\hline Nutrition type & Number of Subjects & Mean \pm SD values \\
\hline Veg & 15 & $-0.96 \pm 0.6$ \\
\hline Non-veg (3 times in week) & 22 & $1.29 \pm 0.92$ \\
\hline Non-veg (more than 3 times in week) & 28 & $1.3 \pm 0.77$ \\
\hline Mixed (Veg/Non-veg) & 15 & $1.38 \pm 0.77$ \\
\hline
\end{tabular}

(Table5) BMD distribution due to sun exposure shows that, BMD level significantly increased in people exposed to sunlight for more than 10 minutes when compared to less expose to sunlight.

Table-5: BMD distribution in relation to sun exposure

\begin{tabular}{|l|l|l|l|}
\hline Sun exposure & Less than 10 mints & More than 10 mints & P -value \\
\hline Before $1 \mathrm{pm}$ & $0.86 \pm 0.7$ & $1.28 \pm 0.8$ & $<0.003$ \\
\hline After $1 \mathrm{pm}$ & $1.16 \pm 0.5$ & $1.34 \pm 0.6$ & $<0.002$ \\
\hline
\end{tabular}

\section{DISCUSSION}

The dietary habit of the participants who were considered as a rural population in the kanchipuram district reflected the eating habit with limited food sources. Their main food sources for veg and non-veg reflected the lifestyle of the study population. $19 \%$ people of both sexes were selected who are vegetarian, $28 \%$ people were selected who take non-veg three 
times in a week, and $35 \%$ people were selected who take non veg more than 3 times in a week and $18 \%$ people were selected who take both veg and non-veg in a week. The results indicate that vegetarian taking people were got low BMD levels when compared to other groups. The results were consistent with previous study in adult Thai subjects living in urban area (Bangkok metropolitan) and in the Chinese and Hong Kong population [9-11], confirmed that a low dietary intake of vitamin D and calcium persists in an Asian population especially in those who lived in rural area. Moreover, decreasing in vitamin D and calcium intake was also observed with advancing age. The low vitamin $\mathrm{D}$ and calcium intake may compromise the rate of bone loss especially in postmenopausal women and in the elderly.

During exposure to sunlight, UVB radiation $(290-315 \mathrm{~nm})$ is absorbed by 7-dehydrocholesterol that is present in the plasma membranes of both epidermal keratinocytes and dermal fibroblasts [12]. The energy is absorbed by the double bonds in the $\mathrm{B}$ ring, which results in rearrangement of the double bonds and opening of the $\mathrm{B}$ ring to form previtamin D3. Once formed, previtamin D3, which is entrapped within the plasma membrane lipid bilayer, rapidly undergoes rearrangement of its double bonds to form the more thermodynamically stable vitamin D3. During this transformation process, vitamin D3 is ejected from the plasma membrane into the extracellular space [12]. The vitamin D-binding protein in the dermal capillary bed has an affinity for vitamin D3 [13] and draws it into the circulation. The principal function of vitamin $\mathrm{D}$ in calcium homeostasis is to increase calcium absorption from the intestine. In the present study indicate that, BMD level significantly increased in people exposed to sunlight for more than 10 minutes when compared to less expose to sunlight.

Experimental studies suggested that, the structural changes of the femur of vitamin D deficient rats after 10 days sun exposure. Trabecular thickness and number were improved together with a reduction of bone marrow spaces. Objective measurements of osteoid area and trabecular separation in Sd subgroups before and after sun exposure revealed a significant increase in osteoid area and a significant decrease in trabecular separation.

Burger $\mathrm{H}$ et al. shows that, yearly percentage BMD reduction in women and men was $-0.6 \%$ and $0.3 \%$ in the femoral neck, $-0.8 \%$ and -0.5 in the Ward's triangle and $-0.4 \%$ and $-0.3 \%$ in the trochanter, respectively.

Warming L et al. suggested that, in women after menopause and in men an age-related bone loss $(0.002-0.006 \mathrm{~g} / \mathrm{cm} 2 /$ year) was found at all sites.
Data were expressed in Mean \pm SD. 25 males in this group $(0.44 \pm 1.0)$ and 20 females in this group $(0.62 \pm 0.98)$ were found to be normal. 11 males in this group $(-1.5 \pm 0.26)$ and 15 females in this group $(-1.7 \pm$ $0.42)$ were found to be osteopenic. 4 males in this group $(-2.65 \pm 0.29)$ and 5 females in this group $(-2.82 \pm 0.32)$ were found to be osteoporotic.

People in the age group of 30-45 years were found to be more osteopenic particularly very high in females (males $-0.97 \pm 1.2$ and females $-1.3 \pm 1.45$ ) and people in the age group 61 to 75 years, were found to be osteoporotic (males $-1.43 \pm 1.3$ and females $-2.08 \pm 0.95$ ) when compared to people in the age group 46-60 years (male $-0.86 \pm 1.3$ and female $-0.45 \pm 1.6$ ).

\section{CONCLUSION}

This study has proved that irrespective of the age, females are found to have lower BMD when compared to males. In the middle age group between 46 to 60 years, people are found to be normal. This study confirms that people of younger age group (30-45 years) are found to be more osteopenic when compared to the older age group (46-60 years) due to of less exposure in sunlight and low intake of vitamin D and calcium diets. Highlight of this study is "Osteopenia is more prevalent in the younger age group which necessitates earlier intervention"

\section{ACKNOWLEDGEMENTS}

I wish to thank the Meenakshi Medical College Hospital and Research for granting me permission and financial support to carry out the project.

\section{CONFLICT OF INTEREST}

The authors declare that there is no conflict of interests regarding the publication of this manuscript.

\section{REFERENCE}

1. Johnell, O., \& Kanis, J. A. (2006). An estimate of the worldwide prevalence and disability associated with osteoporotic fractures. Osteoporosis international, 17(12), 1726-1733.

2. Melton III, L. J., Atkinson, E. J., O'Connor, M. K., O'Fallon, W. M., \& Riggs, B. L. (1998). Bone density and fracture risk in men. Journal of Bone and Mineral Research, 13(12), 1915-1923.

3. MeltonLJ, C. E., \& Cooper, C. (1992). How many women have osteoporosis. J Bone Miner Res, 7, 1005-10.

4. Kanis, J. A., Johnell, O., Oden, A., Sernbo, I., Redlund-Johnell, I., Dawson, A., ... \& Jonsson, B. (2000). Long-term risk of osteoporotic fracture in Malmö. Osteoporosis international, 11(8), 669 674.

5. Koester, K. J., Barth, H. D., \& Ritchie, R. O. (2011). Effect of aging on the transverse toughness of human cortical bone: evaluation by $\mathrm{R}$ - 
curves. Journal of the mechanical behavior of biomedical materials, 4(7), 1504-1513.

6. Kruzic, J. J., \& Ritchie, R. O. (2008). Fatigue of mineralized tissues: cortical bone and dentin. Journal of the mechanical behavior of biomedical materials, 1(1), 3-17.

7. Fantner, G. E., Rabinovych, O., Schitter, G., Thurner, P., Kindt, J. H., Finch, M. M., ... \& Rangelow, I. W. (2006). Hierarchical interconnections in the nano-composite material bone: Fibrillar cross-links resist fracture on several length scales. Composites Science and Technology, 66(9), 1205-1211.

8. Holick, M. F. (1994). McCollum Award Lecture, 1994: vitamin D-new horizons for the 21st century.

9. Ho, S. C., Leung, P. C., Swaminathan, R., Chan, C., Chan, S. S. G., Fan, Y. K., \& Lindsay, R. (1994). Determinants of bone mass in Chinese women aged 21-40 years. II. Pattern of dietary calcium intake and association with bone mineral density. Osteoporosis International, 4(3), 167-175.
10. Hu, J. F., Zhao, X. H., Jia, J. B., Parpia, B., \& Campbell, T. C. (1993). Dietary calcium and bone density among middle-aged and elderly women in China. The American journal of clinical nutrition, 58(2), 219-227.

11. Komindr, S., Piaseu, S., Pattamakom, V., \& Choroenkiatkul, S. (1991). Calcium status and factors relating to bone mineral content in normal Thais living in Bangkok. In Proceeding 10th Annual Meeting of the Thai Royal College of Medicine (Vol. 61).

12. Holick, M. F., Tian, X. Q., \& Allen, M. (1995). Evolutionary importance for the membrane enhancement of the production of vitamin D3 in the skin of poikilothermic animals. Proceedings of the National Academy of Sciences, 92(8), 31243126.

13. Haddad, J. G., Matsuoka, L. Y., Hollis, B. W., Hu, Y. Z., \& Wortsman, J. (1993). Human plasma transport of vitamin $\mathrm{D}$ after its endogenous synthesis. The Journal of clinical investigation, 91(6), 2552-2555. 